\title{
The influenza conundrum
}

The first isolation of a human influenza virus in 1933 [1] heralded the prospect that a vaccine could be produced and influenza ultimately vanquished. The spectre of the human devastation caused by the 1914 1918 war, and then by the catastrophic 1918-1919 influenza pandemic, kindled that prospect. In the event, pandemic influenza turned out to be caused by an antigenically unstable type $\mathrm{A}$ influenza virus. A pandemic is marked by the dramatic substitution of the principal surface antigen, the haemagglutinin $(\mathrm{H})$ which is responsible for the production of neutralising antibodies, while the other surface antigen, the neuraminidase $(\mathrm{N})$, may or may not be substituted. The $\mathrm{H}$ and $\mathrm{N}$ antigens indicate the subtype of the virus.

Since the pandemic that followed World War 1, there have been three more pandemics: in 1957 (H2N2), 1968 (H3N2) and in 1977, when the H1N1 virus the same subtype as the virus that apparently caused the 1918-19 pandemic - mysteriously reappeared. Meanwhile, interpandemic influenza seasons unfailingly come and go around the globe with yearly regularity.

In the interpandemic period both antigens, $\mathrm{H}$ more so, undergo minor changes. These changes probably derive largely from replication errors of the virus's segmented, single stranded RNAs due to a lack of proof reading by the viral RNA polymerases. Thus, in the interpandemic period the virus is often one antigenic change ahead of the influenza A virus variant in the current vaccine somewhere in the world. The east Asian region, particularly China, is important for it is here that new variants are often first detected.

To grapple with this situation, the World Health (Organisation (WHO) has about 110 National Influenza cintres around the world reporting to WHO Collaboratting Centres in London, Atlanta and Melbourne. By plotling the antigenic changes of these influenza $A$ viruses as they move globally, it is now possible for WHO to make recommendations with a high degree of accuracy on the composition of the influenza vaccine for the upcoming influenza seasons in the northern and southern hemispheres. These vaccines have proved broadly effective particularly for the elderly and those at risk [2], as well as reducing absenteeism in the workforce [3].

While errors in replication are largely responsible for antigenic changes in the interpandemic period, it would be genetically impossible for these to account for the sudden change in $\mathrm{H}$ or $\mathrm{N}$ or both subtypes that occurs when a new pandemic virus emerges. New understanding suggests that genetic factors are involved, but by a process of gene re-assortment in which a prevailing human influenza virus and an avian influenza virus co-infect a host and reassort their eight RNA segments to give rise to a novel, re-assortant pandemic virus $[4,5]$.

The host in which this mixing of influenza A viruses most likely takes place is the domestic pig [6], for the pig has receptors for both avian and human influenza viruses [7; R.G. Webster personal communication]. The most likely place for this to occur is in China, particularly southern China, for it is here that there are large human and animal populations living in close proximity in rural areas. The prime host is the domestic duck, in which the virus lives asymptomatically in the intestine, shedding virus into flooded rice fields and ponds. Influenza $A$ viruses abound in the rural environment, favouring interspecies transmission [8-10]. In effect, the domestic pig of China probably acts as intermediate host for the adaptation and subsequent transmission of an avian influenza $A$ virus to man in the guise of a pandemic virus. The significance of rural China is all the more poignant when it is considered that around one in every seven persons in the world is a farmer, or lives in a farming setting, in China.

These and more recent observations, in which avian H1N1 viruses have been found in pigs from southern China [11], have added fuel to the hypothesis that China is an influenza epicentre for the emergence of pandemic viruses [12]. Important as China has been in the emergence of pandemic viruses and interpandemic variants, the possibility that a pandemic virus could arise anywhere that humans are in close association with birds, pigs and perhaps other animals, cannot be excluded [13]. The displacement of classical H1N1 influenza viruses by avian H1NI influenza viruses in pigs in Europe since the late 1970s [14] is highly relevant here.

Predicting the next pandemic is complex, for it involves variables that do not apply to other viruses: where will the virus emerge? When will this occur? In what host might it be first detected? And, most 
importantly, what will be its $\mathrm{H}$ and $\mathrm{N}$ subtypes? A tall order.

The $H$ subtype of the next pandemic virus is something of a lottery. If there is a recycling of $\mathrm{H}$ subtypes based on the $\mathrm{H}$ subtypes of this century, then it must be the $\mathrm{H} 2$ subtype similar to the $\mathrm{H} 2 \mathrm{~N} 2$ virus that prevailed from 1957-1968. If not, it could be any one of the subtypes H4-H15. Based on frequency of occurrence of $\mathrm{H}$ subtypes of viruses detected in ducks in an earlier surveillance study, the $\mathrm{H} 4$ subtype is a leading candidate $[9,10]$. The precedent for this is that $\mathrm{H} 3$, the subtype of the Hong Kong pandemic virus of 1968 , is the second most common H subtype in the ducks of southern China [9].

Serological evidence of human exposure to avian influenza viruses in rural southern China might be another guide [9, 10]. This is difficult to interpret in that a high incidence of antibody to one $\mathrm{H}$ subtype, as in the case of $\mathrm{H} 7$, could simply mean that it is a subtype ill-suited to the potential human host, which may have mounted a strong immune response following mucosal exposure. On the other hand, subtypes for which there appear to have been less human exposure such as H4, H5, H6, H8, H9, H12 and H13, might be more accommodated by humans.

As the first sign of a pandemic will probably be outbreaks of human respiratory disease in China, maximum surveillance effort must be directed toward the isolation of the putative or actual pandemic virus from human patients in that country rather than from the hypothetical, porcine intermediate host. Indeed, there is increased awareness by the global surveillance network of National Influenza Centres, especially the one in Beijing, of the possibility of a new pandemic. Currently, Health and Anti-Epidemic Stations in Harbin, Hohhot, Beijing, Shanghai, Wuhan, Xian, Chengdu, Fuzhou, Shenzhen and Nanning undertake surveillance through the Beijing centre, providing a reasonable coverage of China, while a Department of Health laboratory deals solely with the Special Administrative Region of Hong Kong. All eleven of these regional laboratories are acutely aware of the situation.

This level of surveillance is a far cry from the situation in 1968 when China was largely a closed country and the $\mathrm{H} 3 \mathrm{~N} 2$ pandemic virus was first isolated in Hong Kong [15]. Even so, with the increased movement of people in China and the extensive international business and tourist air travel to and from the country [16], the new pandemic virus could emerge at a site in China distant from its point of origin, in Asia or on the other side of the globe, highlighting again the importance of the global network of National Influenza Centres in monitoring the disease.

Whatever the case, the Hong Kong influenza era is 29 years old and each year brings us closer to the next pandemic. With global surveillance systems now in place, there is the prospect of getting ahead of the next pandemic virus for the first time ever, an ideal promoted a quarter of a century ago by Professor Sir Charles Stuart-Harris [17]. Now that the pig is recognised as a possible intermediate host in the genesis of pandemic viruses, surveillance of pigs for novel influenza viruses, particularly in China, might provide an early warning system. This is a totally new approach with its own logistical and epidemiological problems; none the less preliminary steps in surveillance are being made.

Given the present awareness of the public and the media about emerging and re-emerging infectious diseases including influenza, it is important that there are no false alarms on the emergence of a pandemic. The declaration of a potential pandemic situation should be soundly based, unambiguous, and come directly from the WHO.

In preparing for an impending pandemic, the emphasis for control must still be on prevention rather than treatment. The established antiviral agents, amantadine and rimantadine, are not particularly practical in that they must be given prophylactically and are of limited availability, except in China where amantadine can usually be purchased over the counter. However, the new neuraminidase inhibitor, GG167 [18], is not only active prophylactically, but has significant antiviral effect in early treatment [19]. Should the next pandemic emerge later rather than sooner, GG167, and perhaps other agents in the offing, might find a place in treatment or, more likely, as an adjunct to vaccination.

For the present, conventional vaccination remains the only practical approach toward control. The new vaccine must of necessity be monovalent for the pandemic virus at least until the pandemic settles down and new variants emerge. If, as occurred with the 1968 Hong Kong outbreak, the pandemic virus emerges from China during the summer [15] - the peak period for influenza in southern China [20] there may just be sufficient time to manufacture adequate stocks of vaccine for the northern hemisphere winter. If the virus emerges in late summer, this may be less certain. The situation with the southern hemisphere, notably Australasia, is quite different in that their winter coincides with the northern summer so that a pandemic virus could conceivably take hold forthwith should it emerge in China in late spring or early summer. Whatever the case, there will be considerable difficulties for China in preparing adequate vaccine in time $[16,20]$.

New elements affecting the behaviour of the pandemic and the outcome of vaccination could arise in the next pandemic. In previous pandemics there was only one 
virus subtype to replace, whereas now there are two: $\mathrm{H} 3 \mathrm{~N} 2$ and $\mathrm{H} 1 \mathrm{~N} 1$. If only one virus subtype is replaced, would the pandemic virus re-assort with the remaining one? If the $\mathrm{H}$ subtype of the virus is $\mathrm{H} 2$ and the virus emerges in, say, 1997, would those presently aged c. 29-40 years who had been exposed to the Asian family of viruses have some immunity to ameliorate the effect of the pandemic? What might be the significance of a pandemic virus in which only the $\mathrm{N}$ subtype was substituted?

Public health authorities in several countries have prepared plans for dealing with vaccine production, its acquisition and quantity, vaccination policy, dissemination of information and so on. Different and difficult public health issues could arise nationally and globally. Of major importance is the need for sound guidelines on the use of antibiotics to control secondary bacterial infection. While pandemic influenza itself may not be life-threatening in otherwise healthy individuals, subsequent bacterial pneumonia caused by Staphylococcus aureus or Streptococcus pneumoniae is. Given the increasing resistance of $S$. aureus to antibiotics in many parts of the world, serious treatment problems could arise. Regularly updated guidelines on the use of antibiotics should be part of pandemic preparedness.

K. F. SHORTRIDGE Department of Microbiology, The University of Hong Kong, University Pathology Building, Queen Mary Hospital Compound, Pokfulam, Hong Kong

\section{References}

1. Smith W, Andrewes $\mathrm{CH}$, Laidlaw PP. A virus obtained from influenza patients. Lancet; 2: 66-68.

2. Ahmed AEH, Nicholson KG, Nguyen-Van-Tam JS. Reduction in mortality associated with influenza vaccine during the 1989-90 epidemic. Lancet 1995; 346; 591-595.

3. Nichol KL, Lind A, Margolis KL et al. The effectiveness of vaccination against influenza in healthy, working adults. $N$ Engl $J$ Med 1995; 333: 889-893.

4. Webster RG, Laver WG. Antigenic variation of influenza viruses. In: Kilbourne ED (ed) The influenza viruses and influenza. New York: Academic Press. 1975: 269-314.

5. Kawaoka Y, Krauss S, Webster RG. Avian-to-human transmission of the PB1 gene of influenza A virus in the 1957 and 1968 pandemics. J Virol $1989 ; 63$ : $4603-4608$.

6. Scholtissek $C$, Bürger $H$, Kistner $O$, Shortridge KF. The nucleoprotein as a possible major factor in determining host specificity of influenza H3N2 viruses. Virology 1985; 147: $287-294$.

7. Ito $\mathrm{T}$, Kida $\mathrm{H}$, Kawaoka Y. Receptors of influenza A viruses: implications for the role of pigs for the generation of pandemic human influenza viruses. In: Brown LE, Hampson AW, Webster RG (eds) Options for the control of influenza III. (3rd International Conference for the control of influenza. Cairns, Australia, 4-9 May 1996). Amsterdam, Elsevier. 1996: 516519.

8. Shortridge KF, Stuart-Harris $\mathrm{CH}$. An influenza epicentre? Lancet 1982; 2: 812-813.

9. Shortridge KF. Pandemic influenza - a zoonosis? Semin Respir Infect 1992; 7: 11-25.

10. Shortridge KF. The next pandemic influenza virus? Lancet 1995; 346: 1210-1212.

11. Guan Y, Shortridge KF, Krauss S, Li PH, Kawaoka Y, Webster RG. Emergence of avian $\mathrm{H} 1 \mathrm{Nl}$ influenza viruses in pigs in China. J Virol 1996; 70: 8041-8046.

12. Shortridge KF. Is China an influenza epicentre? Chin Med $J$ 1997; 110 (in press).

13. Bonn D. Spared an influenza pandemic for another year? Lancet 1997; 349: 36.

14. Claas ECJ, Kawaoka Y, de Jong C, Masurel N, Webster RG. Infection of children with avian-human reassortant influenza virus from pigs in Europe. Virology 1994; 204: 453-457.

15. Chang WK. National influenza experience in Hong Kong 1968. Bull World Health Organ 1969; 41: 349-351.

16. Shortridge KF. Influenza, Hong Kong, and the China traveler. $J$ Travel Med 1995; 2: 257-259.

17. Stuart-Harris CH. Pandemic influenza: an unsolved problem in prevention. J Infect Dis 1970; 122: 108-115.

18. von Itzstein $\mathrm{M}$, Wu WY, Kok GB et al. Rational design of potent sialidase-based inhibitors of influenza virus replication. Nature 1993; 363: 418-423.

19. Hayden FG, Treanor JJ, Betts RF, Lobo M, Esinhart JD, Hussey EK. Safety and efficacy of the neuraminidase inhibitor GG167 in experimental human influenza. JAMA 1996; 275: 295-299.

20. Reicheldelfer P, Kendal AP, Shortridge KF, Hampson A. Influenza surveillance in the Pacific Basin. Seasonality of occurrence: a preliminary report. In: Chan $\mathrm{YC}$, Doraisingham $\mathrm{S}$, Ling AE (eds) Proceedings of the first Asia-Pacific congress of medical virology. Singapore. Singapore, World Scientific 1989: 412-444. 